\title{
Determination of the Content Heavy Metals in of Introduced Tree Stand of Astana City
}

\author{
Erzhan Zhunusovich Kentbayev ${ }^{1}$, Botagoz Aidarbekovna Kentbayeva ${ }^{1} \&$ Talgat Sagidollaevich Abzhanov ${ }^{1}$ \\ ${ }^{1}$ Department of forest resources and hunting, The Kazakh National Agricultural University, Almaty, Kazakhstan \\ Correspondence: Talgat Sagidollaevich Abzhanov, Department of forest resources and hunting, The Kazakh \\ National AgriculturalUniversity, 050010, Abai Avenue 8, Almaty, Kazakhstan. Tel: 871-7272-4350. E-mail: \\ taka_777@mail.ru
}

Received: January 9, 2015

Accepted: March 20, $2015 \quad$ Online Published: June 25, 2015

doi:10.5539/mas.v9n8p121

URL: http://dx.doi.org/10.5539/mas.v9n3p121

\begin{abstract}
Nowadays, the importance of determining the numericalvaluation of environmental and genetic structure of populations of woody tree species in dealing with the introduction, without any doubt, is recognized by many researchers. The growing numbers of works associated with the introduction, examination of geographic cultures focused on the study of interspecific, inter- and intrapopulation, subpopulation genetic structure of quantitative and qualitative attributes which are important for forestry production and industrial wood processing. Heavy metals that were included in the scientific literature in the middle of the last century under such a negative name, at current stage already occupy the second place in the hazard level. In the future they might become the most hazardous or even more hazardous than APS and solid wastes. Contamination with heavy metals occurs due to their wide use in industry, causing them to fall into the environment bringing enormous damage. Human activity always brings to formation of numerous volumes of waste, including toxic. Industrial enterprises and large number of vehicles - obligatory accompaniments of urban environment are the major and permanent "suppliers" of toxic waste into the atmosphere. Under normal conditions, heavy metals are contained in soil in small quantities and are not hazardous. However, their concentration may increase due to vehicle exhaust, waste, residues and emissions during operation of industrial plants, during fertilize, etc.
\end{abstract}

Keywords: heavy metals, caragana arborescens, introduced

\section{Introduction}

An introduction is a transfer of plants from one region to the region where they were missing with the use of impactmethods to the nature. The possibility of introduced plants to acclimate was pointed out by many researchers (Nicholaevsky V.S., 1979, Sergeichik S.A., 1997). However, the naturalization (the transfer of plants to the similar habitats) was more recognized for a long time, which also denies the ability of the plant to adapt to the new conditions.

In 1868, at the initiative of the nobility, the local intelligentsia, amateur gardenersfrom Voronezh, Kharkov, Penza province, as well as Nicholas Botanical Garden, plants, which are several varieties of apple, grape, lilac, oak, marpleplatanoides, mountain ash, horse chestnut, quince, ailanthus, Japanese acacia, were brought. It was the spontaneous introduction. In 1868, Vernenskaya Grove was established by order of the General Governor Kolpakovsky and the scientist and forester E.O. Baum. By 1879 it had an area of 152 acres, including a forest nursery. In 1871, the seeds of pine and larch were produced, and, in 1874, seeds of white and yellow acacia, hawthorn, ash, mulberry were experimentally planted. In the same year, Moscow received seeds of Pinus pinaster, P.peuce, P. strobus, P. cembra, Thuja occidentalis, Juniperus virginiana (Semakin V.P., 1968, Vazhenin I.G., 1987, GOST (State Standards) 1983, SanPin 2002, Clausen, K.E., 1984).

Climatic conditions: Factors and ecological conditions of soil formation and landscape environment. The geographical position of Astana is led by the severity of extreme continental climate and its instability. Winter is cold and long with a steady snowing. Summer is relatively short, but hot with low precipitation and strong evaporation. Sharp continental climate is due to the remoteness of the area from major water ponds and the closeness to the desert and semi-desert areas of Central Asia and the polar regions of Siberia (Bridgwater F.E., et.al., 1983, Birot Y., et.al., 1983, Pollard D.F. et.al., 1974, Stastny T. 1971). 


\section{Materials and Methods}

\subsection{Basic Methods of Introduction and Acclimatization of Plants}

After studying the flora of Central America (1799-1804) A. Humboldt drew attention to the relationship between the distribution of plants and climatic conditions. He was the first to point out that the acclimatization of plants should take into account not just the average temperature but the amount of temperature above $0^{\circ} \mathrm{C}$ during the growing season (Shimadzu 2008, Wilcox M.D., 1991, Burdon R. D., et.al., 1973, Maronek D.M., et.al., 1974, Campbell R. K., 1974,). For successful acclimatization it should not be less than it was at home conditions. Humboldt paid attention to other climatic factors of habitats of plants, such as average temperature, humidity, pressure and air transparency. He believed that these factors would affect the distribution of plants. In this regard, he suggested the vertical and horizontal zonation of vegetation. Humboldt proposed the method of gradual acclimatization of plants, later called the step acclimatization, which is moving plants from one climate to another, by growing them at intermediate stations (Vincet G., 1974, Krutzsch P., 1975, Eriksson G., et al., 1975, Giertych M., 1976, Szonyi L., et al.,1975, Guidelines., All-Union Scientific Research Institute of Mineral Raw Materials. (AIMRM), 1991).

\section{Results and Discussion}

\subsection{Evaluation of introduced species on Bio Morphological Parameters of Leaf Blades}

Plants growing in a large city are influenced by many different factors. It is especially painful for plants to tolerate exposure to man-made factors, an essential condition of civilization. Conditions of the natural habitat of plants are radically different from those of the city.

The plants, which were grown at the best environments, adapt and often survive in extreme conditions by changing not only the biological and physiological processes, but biological and morphological parameters, the anatomical structure that is reflected in the change of habitus, shape and size of the leaf blades, fruit, etc.

\subsection{The Length of the Leaf Blades}

The length of the leaf blades is the main parameter which determines their size and shape. We studied the length of the leaf blades of 13 species of plants which were growing at three test sites. Research and statistics of materials are given in Tables 1, 2, 3. The value of the error in mean showsrelatively narrow confidence limits, which indicatesa highly accurate obtained value. The arithmetic means was calculated as a criterion for evaluation of the entire group of plants.

On the first test site, all plants formed a complete leaf blade except Acer ginnala, on the second site - all the plants, and the third section -Juglans mandshurica and Saragana arborescens did not form leaf blades. Length of the leaf blades of Fraxinus excelsior L., which was planted on the test sites, varies within the following limits: 1test site $-66.90 \mathrm{~mm}, 2$ test site $-71.27 \mathrm{~mm}, 3$ site $-86.00 \mathrm{~mm}$. Populus simonii had the longest leaves on the first test site $-55.83 \mathrm{~mm}$. Prunus divaricata, Salix babilonica, Saragana arborescens, Populus simonii, Radus aviumare the leaders on the length of the leaf blades of the first test site (Figure 1).

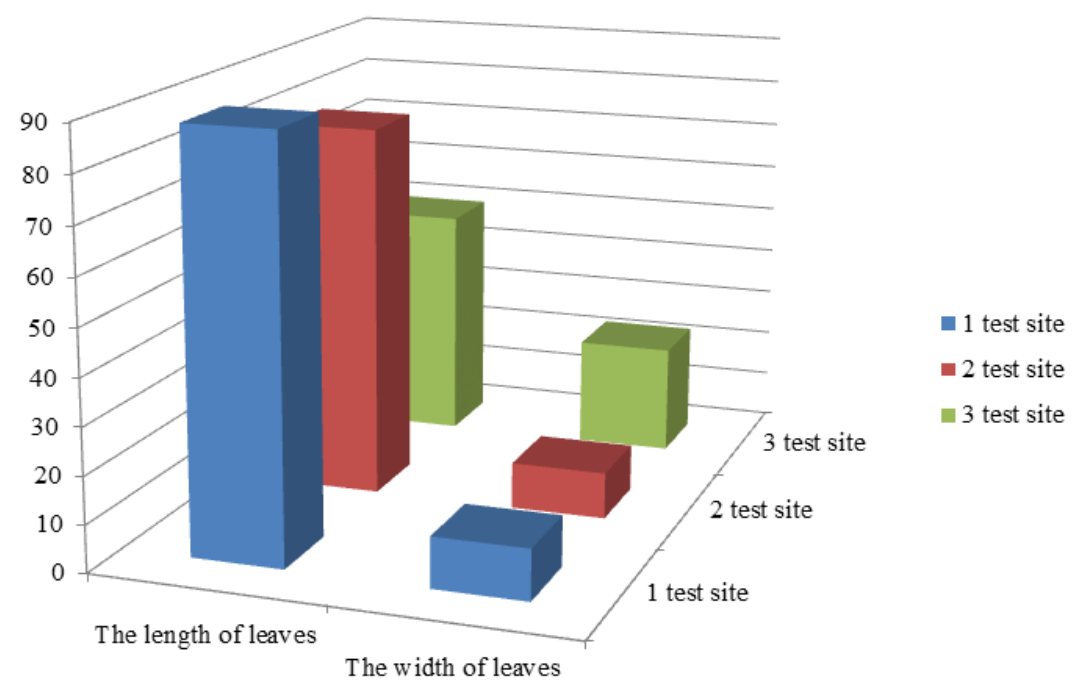

Figure 1. Linear parameters of leave blades of Salix babilonica from tree test sites 
Ranking the objects of study according to the length of leaves revealed the plants, which had maximum value: Amorpha fruticosa, Phellodendron amurense, Gled itsiatriacanthos, Acer ginnala, Mahonia aquifolia, Juglansmands hurica, Forsythia xintermedia Zabel. According to the arithmetic mean data, they formed the longest leaves on the second site (Figure 2).

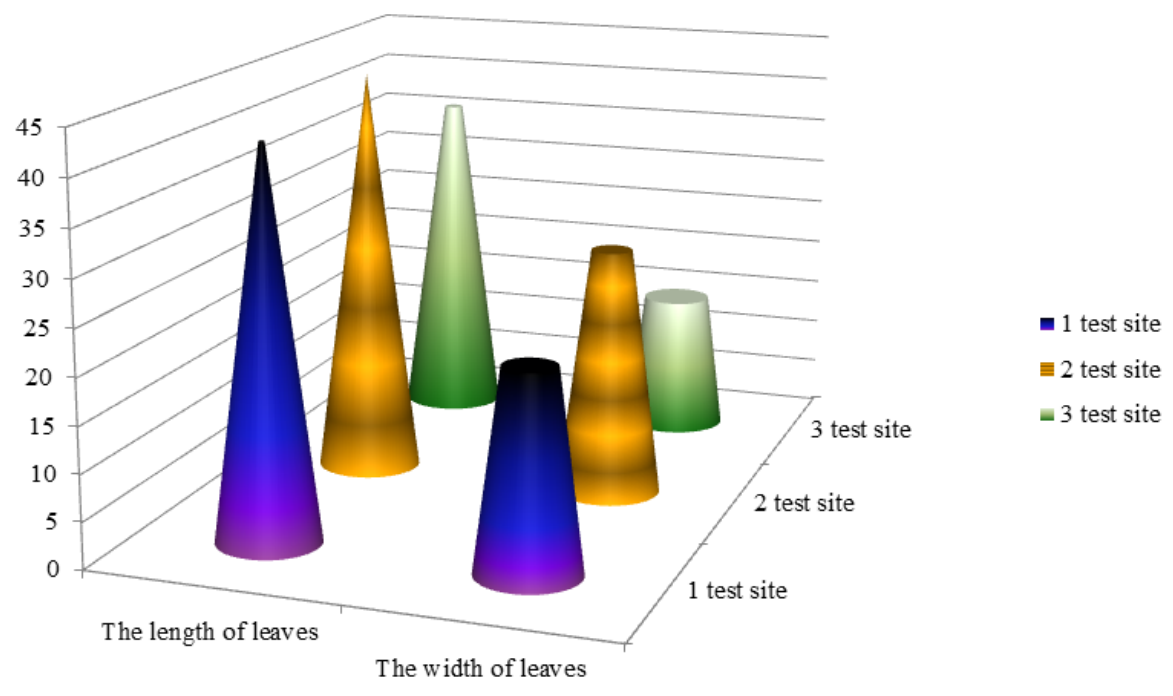

Figure 2. Linear parameters of leave blades of Mahonia aquifolia from tree test sites

Leading positions according to the length of the leaf blades of the first test siteare occupied by Saragana arborescens, Prunus divaricata, Salix babilonica, Populus simonii, Radus avium.

The highest values of the arithmetic means of the width of the second site of leaves belong to Amorpha fruticosa, Phellodendron amurense, Gled itsiatriacanthos, Acer ginnala, Mahonia aquifolia, Juglans mandshurica.

In the third site, only two species, a Fraxinus excelsior L. and Forsythia xintermedia Zabel, have a predominance of the width of the leaf blade.

Percentage ratio of the number of plants with a maximum length of leaf blades on the first site is $38.47 \%$, in the second site $-46.16 \%$, and the third site $-18.19 \%$.

The average level of variation coefficients dominates on the first and third sites in 8-cases. The width of the leaf blades of the studied plants have a low, medium and upper level of variability, measured by the values of the variation coefficients according to the scale of variability. On the first site the medium level of variation is 5 cases out of 12, a low level - 4 cases out of 12, an upper level is 3 out of 12 cases (Acer ginnala has not formed leaves). According to the second site results, 5 plants have the low level of variability, 8 plants - the average level, and no plants have an upper level. In the third site, 2 types of experimental plants did not form leaves (Saragana arborescens, Juglans mandshurica), 1 case with low level of variation, 8 cases of medium variation and 3 cases of upper variation. Limits vary widely.

Accuracy of the experiment in all cases is less than $5 \%$ level, which indicates the high accuracy of the experiments.

From the tables and visual observations we can say that the subjects are characterized by linear parameters of the leaf blades. The wide range of studied plants is characterized by a high degree of environmental heterogeneity. Differences were found in all areas which are mostly characterized as significant within the same type of planting. However, significant differences were found among species growing on different sites. Relatively favorable conditions for planting in the park area, which is protected from the negative effects of transport and other human impact, had a positive effect on the growth and development of plants, in general, and on the change in individual organs, in particular. 
Table 1. Length and width of the leaf blades of inducted woody plants on the 1 test site

\begin{tabular}{|c|c|c|c|c|c|c|}
\hline \multirow[t]{2}{*}{$\mathrm{N}$} & \multirow[t]{2}{*}{ Name of woody plant species } & \multirow{2}{*}{$\begin{array}{l}\text { Arithmetic mean } \\
\mathrm{M} \pm \mathrm{m}, \mathrm{mm}\end{array}$} & \multirow{2}{*}{$\begin{array}{l}\text { Variability } \\
\text { index, } \mathrm{Cv}, \%\end{array}$} & \multirow{2}{*}{$\begin{array}{l}\text { Test accuracy, } \\
\mathrm{P}, \%\end{array}$} & \multicolumn{2}{|c|}{ Limits } \\
\hline & & & & & $\min$ & $\max$ \\
\hline \multirow[t]{2}{*}{1} & Caragana arborescens & $20,80 \pm 0,65$ & 17,08 & 3,12 & 14 & 25 \\
\hline & (f. pendula) & $10,03 \pm 0,26$ & 14,44 & 2,64 & 7 & 13 \\
\hline \multirow[t]{2}{*}{2} & Prunus divaricata & $34,13 \pm 1,59$ & 25,58 & 4,67 & 20 & 50 \\
\hline & & $14,87 \pm 0,70$ & 25,86 & 4,72 & 10 & 22 \\
\hline \multirow[t]{2}{*}{3} & Amorpha fruticosa & $22,80 \pm 0,91$ & 21,85 & 3,99 & 11 & 30 \\
\hline & & $9,83 \pm 0,45$ & 25,20 & 4,60 & 7 & 13 \\
\hline \multirow[t]{2}{*}{4} & Phellodendron amurense & $75,57 \pm 2,20$ & 15,96 & 2,91 & 60 & 102 \\
\hline & & $32,73 \pm 0,70$ & 11,72 & 2,14 & 27 & 40 \\
\hline \multirow[t]{2}{*}{5} & Gled itsiatriacanthos & $28,33 \pm 1,17$ & 22,66 & 4,14 & 15 & 36 \\
\hline & & $11,57 \pm 0,34$ & 15,89 & 2,90 & 8 & 14 \\
\hline \multirow[t]{2}{*}{6} & Salix babilonica & $88,17 \pm 4,18$ & 25,95 & 4,75 & 55 & 145 \\
\hline & & $10,77 \pm 0,50$ & 25,34 & 4,63 & 8 & 18 \\
\hline \multirow[t]{2}{*}{7} & Acer ginnala & - & - & - & - & - \\
\hline & & - & - & - & - & - \\
\hline \multirow[t]{2}{*}{8} & Mahonia aquifolia & $42,10 \pm 0,87$ & 11,31 & 2,07 & 35 & 52,0 \\
\hline & & $21,70 \pm 0,77$ & 19,52 & 3,56 & 15 & 30,0 \\
\hline \multirow[t]{2}{*}{9} & Juglans mandshurica & $49,20 \pm 1,09$ & 12,17 & 2,22 & 41 & 63,0 \\
\hline & & $25,30 \pm 065$ & 14,15 & 2,58 & 19 & 32 \\
\hline \multirow[t]{2}{*}{10} & Populus simonii & $55,83 \pm 2,08$ & 20,43 & 3,7 & 29 & 75 \\
\hline & & $34,00 \pm 1,38$ & 22,23 & 4,08 & 21 & 47 \\
\hline \multirow[t]{2}{*}{11} & Forsythia xintermedia Zabel & $39,37 \pm 1,57$ & 21,05 & 3,84 & 20 & 49 \\
\hline & & $20,50 \pm 0,80$ & 21,29 & 3,89 & 10 & 25 \\
\hline \multirow[t]{2}{*}{12} & Padus avium & $59,43 \pm 1,63$ & 14,93 & 2,74 & 46 & 74 \\
\hline & & $32,13 \pm 0,48$ & 8,26 & 1,51 & 29 & 37 \\
\hline \multirow[t]{2}{*}{13} & Fraxinus excelsior L. & $66,90 \pm 1,69$ & 13,81 & 2,52 & 50 & 80 \\
\hline & & $18,43 \pm 0,69$ & 20,38 & 3,72 & 14 & 25 \\
\hline
\end{tabular}

Only one type of test plant has the highest value of the length of the leaves in all three areas - a Fraxinus excelsior L. The weak development of the parameters of the leaf blades on the third experimental site is most likely connected with the relative rigidity of the environment in this area of research. All three sites are located in the parks, recreation areas; eco factor complex and mainly watering had a positive effect on the development and status of the leaf blades, which is reflected on the length in this case.

Percentage ratio of the number of plants with a maximum length of leaf blades on test site: 1 test site ( 5 of 12 plants with formed leaves) - 41.67\%, 2 test site ( 7 of 13 plants with formed leaves) - 53.85\%, 3 test site ( 1 of 11 plants with formed leaves) $-9.09 \%$. Plants which were planted on the 1 test site (located in the park near the Presidential Park near Palace of Peace and Reconciliation) and the second test site (located in the park near the shopping and entertainment center "Khan Shatyr") even by visual inspection showed a better rate.

Table 2. Length and width of the leaf blades of inducted woody plants on the 2 test site

\begin{tabular}{|c|c|c|c|c|c|c|}
\hline \multirow{2}{*}{ № } & \multirow{2}{*}{$\begin{array}{l}\text { Name of woody } \\
\text { plant species }\end{array}$} & \multirow{2}{*}{$\begin{array}{l}\text { Arithmetic mean } \\
\mathrm{M} \pm \mathrm{m}, \mathrm{mm}\end{array}$} & \multirow{2}{*}{$\begin{array}{l}\text { Variability } \\
\text { index, Cv, \% }\end{array}$} & \multirow{2}{*}{$\begin{array}{l}\text { Test accuracy, } \\
\mathrm{P}, \%\end{array}$} & \multicolumn{2}{|c|}{ Limits } \\
\hline & & & & & $\min$ & $\max$ \\
\hline \multirow{2}{*}{1} & Caragana arborescens & $16,10 \pm 0,64$ & 21,66 & 3,95 & 10 & 21 \\
\hline & & $8,37 \pm 0,13$ & 8,44 & 1,54 & 7 & 9 \\
\hline \multirow{2}{*}{2} & Prunus divaricata & $33,07 \pm 1,20$ & 19,92 & 3,64 & 21 & 43 \\
\hline & & $13,40 \pm 0,63$ & 25,75 & 4,70 & 8 & 20 \\
\hline \multirow{2}{*}{3} & Amorpha fruticosa & $28,63 \pm 0,57$ & 10,91 & 1,99 & 23 & 33 \\
\hline & & $10,93 \pm 0,23$ & 13,31 & 2,06 & 9 & 13 \\
\hline \multirow{2}{*}{4} & & $84,23 \pm 1,53$ & 9,95 & 1,82 & 73 & 100 \\
\hline & Phellodendron amurense & $35,17 \pm 0,83$ & 12,97 & 2,37 & 31 & 45 \\
\hline \multirow{2}{*}{5} & Gled itsiatriacanthos & $36,97 \pm 1,59$ & 23,53 & 4,30 & 24 & 57 \\
\hline & & $13,43 \pm 0,49$ & 19,95 & 3,64 & 10 & 18,0 \\
\hline
\end{tabular}




\begin{tabular}{|c|c|c|c|c|c|c|}
\hline \multirow{2}{*}{6} & Salix babilonica & $79,27 \pm 3,95$ & 27,32 & 4,99 & 50 & 108,0 \\
\hline & & $9,87 \pm 0,42$ & 23,22 & 4,24 & 6 & 13 \\
\hline \multirow{2}{*}{7} & Acer ginnala & $44,70 \pm 0,98$ & 11,98 & 2,19 & 37 & 54 \\
\hline & & $39,93 \pm 1,07$ & 14,69 & 2,68 & 27 & 47 \\
\hline \multirow{2}{*}{8} & Mahonia aquifolia & $44,53 \pm 0,92$ & 11,28 & 2,06 & 37 & 52 \\
\hline & & $27,10 \pm 0,75$ & 15,20 & 2,77 & 20 & 34 \\
\hline \multirow{2}{*}{9} & Juglans mandshurica & $51,17 \pm 1,38$ & 14,74 & 2,69 & 39 & 65 \\
\hline & & $28,40 \pm 0,85$ & 16,43 & 3,00 & 15 & 36,0 \\
\hline \multirow{2}{*}{10} & Populus simonii & $51,37 \pm 1,61$ & 17,18 & 3,14 & 35 & 65 \\
\hline & & $33,00 \pm 1,14$ & 18,91 & 3,45 & 20 & 42 \\
\hline \multirow{2}{*}{11} & Forcythi yintermedia 7 ghel & $62,07 \pm 2,62$ & 23,13 & 4,22 & 33 & 84 \\
\hline & Forsythia xintermedia Zabel & $31,57 \pm 1,28$ & 22,26 & 4,06 & 9 & 42,0 \\
\hline \multirow{2}{*}{12} & Padus avium & $52,10 \pm 0,96$ & 10,12 & 1,85 & 45 & 60 \\
\hline & & $31,93 \pm 0,90$ & 15,45 & 2,82 & 25 & 40 \\
\hline \multirow{2}{*}{13} & Caragana arborescens & $71,27 \pm 1,44$ & 11,10 & 2,03 & 58 & 82 \\
\hline & & $21,87 \pm 0,87$ & 21,89 & 4,00 & 14 & 36 \\
\hline
\end{tabular}

It is important to mention the differences of maximum and minimum average of leaf length in Phellodendron amurense between sites. The first site's leaf length is $75.57 \mathrm{~mm}$, the second's $-84.23 \mathrm{~mm}$, the length of the leaves of the third portion is $48.63 \mathrm{~mm}$. The range of variation is observed at the level of $35.60 \mathrm{~mm}$. In Salix babilonica, the limit of variability of arithmetic mean is equal to $38.34 \mathrm{~mm}$, in Forsythia xintermedia Zabel - 22, $20 \mathrm{~mm}$.

The trait variability scale according to S.A. Mamaeva levels is estimated by the values of the coefficients of variation and refers to the low, medium and upper level. On the first test site the medium level of variation is dominated - 6 of 12 cases (one kind of plant has not formed leaves - Acer ginnala). According to the second site results 7 plants have the low level of variation, 5 plants - the medium level, the upper level - 1 plant. In the third site there were 4 cases of low level variation, 5 cases of medium variation and 2 cases of upper variation of the 11 plants which have formed leaves.

Table 3. Length and width of the leaf blades of inducted woody plants on the 3 test site

\begin{tabular}{|c|c|c|c|c|c|c|c|}
\hline \multirow[t]{2}{*}{ № } & \multirow{2}{*}{$\begin{array}{l}\text { Name of woody plant } \\
\text { species }\end{array}$} & \multirow{2}{*}{$\begin{array}{l}\text { Arithmetic mean } \\
\mathrm{M} \pm \mathrm{m}, \mathrm{mm}\end{array}$} & \multirow{2}{*}{$\begin{array}{l}\text { Variability } \\
\text { index, Cv, \% }\end{array}$} & \multirow{2}{*}{$\begin{array}{l}\text { Test } \\
\mathrm{P}, \%\end{array}$} & \multirow[t]{2}{*}{ accuracy, } & \multicolumn{2}{|c|}{ Limits } \\
\hline & & & & & & $\min$ & $\max$ \\
\hline \multirow[t]{2}{*}{1} & Caragana arborescens & - & - & & - & - & - \\
\hline & & - & - & & - & - & - \\
\hline \multirow[t]{2}{*}{2} & Prunus divaricata & $30,53 \pm 1,10$ & 19,79 & 3,61 & & 20 & 39 \\
\hline & & $12,93 \pm 0,55$ & 23,19 & 4,23 & & 8 & 18 \\
\hline \multirow[t]{2}{*}{3} & Amorpha fruticosa & $24,03 \pm 1,10$ & 24,98 & 4,56 & & 15 & 30 \\
\hline & & $9,53 \pm 0,45$ & 25,80 & 4,71 & & 5 & 16 \\
\hline \multirow[t]{2}{*}{4} & Phellodendron & $48,63 \pm 2,16$ & 24,30 & 4,44 & & 29 & 65 \\
\hline & amurense & $25,70 \pm 1,18$ & 25,10 & 4,58 & & 16 & 38 \\
\hline \multirow[t]{2}{*}{5} & Gled itsiatriacanthos & $22,50 \pm 1,06$ & 25,83 & 4,72 & & 13 & 31 \\
\hline & & $11,27 \pm 0,53$ & 25,72 & 4,70 & & 5 & 15 \\
\hline \multirow[t]{2}{*}{6} & Salix babilonica & $49,83 \pm 2,37$ & 26,03 & 4,75 & & 30 & 66 \\
\hline & & $6,47 \pm 0,22$ & 18,61 & 3,40 & & 5 & 8 \\
\hline \multirow[t]{2}{*}{7} & Acer ginnala & $31,77 \pm 0,82$ & 14,09 & 2,57 & & 25 & 41 \\
\hline & & $25,10 \pm 0,73$ & 15,85 & 2,89 & & 20 & 33 \\
\hline \multirow[t]{2}{*}{8} & Mahonia aquifolia & $36,47 \pm 0,88$ & 13,17 & 2,40 & & 29 & 44 \\
\hline & & $18,97 \pm 0,55$ & 15,96 & 2,91 & & 15 & 24 \\
\hline \multirow[t]{2}{*}{9} & Juglans mandshurica & - & - & - & & - & - \\
\hline & & - & - & - & & - & - \\
\hline \multirow[t]{2}{*}{10} & Populus simonii & $44,90 \pm 1,64$ & 19,98 & 3,65 & & 30 & 60 \\
\hline & & $24,37 \pm 0,69$ & 15,55 & 2,84 & & 17 & 30 \\
\hline \multirow[t]{2}{*}{11} & Forsythia xintermedia & $61,57 \pm 0,96$ & 8,57 & 1,56 & & 53 & 70 \\
\hline & Zabel & $33,17 \pm 1,31$ & 21,60 & 3,94 & & 27 & 59 \\
\hline
\end{tabular}




\begin{tabular}{lllllll}
\hline 12 & Padus avium & $53,90 \pm 2,15$ & 21,82 & 3,98 & 32 & 70 \\
& & $30,23 \pm 1,43$ & 25,90 & 4,73 & 15 & 41 \\
13 & Caragana arborescens & $86,00 \pm 1,60$ & 10,17 & 1,86 & 73 & 104 \\
& & $30,73 \pm 0,46$ & 8,23 & 1,50 & 25 & 35 \\
\hline
\end{tabular}

Accuracy of the experiment, which shows the correct formulation and implementation of research in all cases, is within an acceptable range and does not exceed 5\%. Maximum and minimum limits, which are the limits can vary within wide range, determines the data indicated in the tables of arithmetic means of 13 kinds of plants.

The width of the leaves. As well as the length, width of the leaves is the main parameter that creates the appearance of plants, reflecting in its shape and area (Table 1,2,3). Leaf width determines its elasticity and promotes opposition to external influence of the nature. During the dry season the leaves of some plants fold their edges, thereby reducing the exposure to the sun and minimizing the rate of evaporation while increasing water-holding capacity. The width of the leaves is a regulatory mechanism and has great practical significance.

Depending on the site the width leaves of Prunus divaricata varies within the following limits: 1 site $-14.87 \mathrm{~mm}$, 2 site $-13.40 \mathrm{~mm}, 3$ site $-12.93 \mathrm{~mm}$. Fraxinus excelsior L. has the widest leaves formed on the third section $30.73 \mathrm{~mm}$.

\section{Conclusion}

The following conclusions can be made based on performed studies:

1. Analysis of the current range of Astana woody plants and forest nursery JSC "Astana Zelenstroy" indicates lack of species diversity. The identified lack admits introduction events in Astana. Based on the study of biological characteristics of woody and shrubby plants, an assortment of 50 woody species can be used in landscaping Astana was formed.

2. Test landings of 13 of 50 species of woody plant introductions were conducted in Astana. Plants imported from the JSC "Forest Nursery" of Almaty region located $53 \mathrm{~km}$ east of Almaty. Pilot group of plants was planted on three experimental sites: Caragana arborescens (f. pendula); Prunus divaricate; Amorpha fruticosa; Phellodendron amurense;Gleditsia triacanthos; Salix babilonica; Acer ginnala; Mahonia aquifolia; Juglans mandshurica; Populus simonii; Forsythia xintermedia Zabel; Padus avium; Fraxinus excelsior L.

The separation of plants for three sites will allow for further full comparative observations of introduced plants growth and development.

The greatest impact of the complex environmental factors were felt by plants of the third test site, which are reflected in the linear parameters of the studied plants.

Thus, we can conclude that the plants which were planted in the environmental sections produce the leaf blades differentiated by the linear parameters. Considering the uniformity of the studied plants we can say that the identified differences in the experiments are strongly influenced by environmental conditions.

\section{References}

Birot, Y. (1983). Christophe C Genetic structures and expected genrtic gains multitrait selection in wild populations of Douglas fir and Sitka spruce. I. Genetic variaton between and within populations. Silvae genet., Bd.32(5-6), 141-151.

Bridgwater, F. E., Talbert, J. T., \& Jahromi, S. (1983). Index selection for increased dry weight in a young loblolly pine population. Silvae Genet., Bd.32(N5-6), 157-161.

Burdon, R. D., \& Bannister, M. H. (1973). Provenances of Pinus radiata: Their earlyperformance and silvicultural potential. N.Z.J. Forestry, 18(N2), 217-232.

Campbell, R. K. (1974). A provenance - transfer model for boreal regions. Medd.Norsk Inst. Skogiorsk., Bd.31(10), 543-566, ill.

Clausen, K. E. (1984). Nonlinear regressions and contour plots: techniques for selection and transfer of white ash provenances. Forest. Sci., 30(N2), 441-453.

Eriksson, G., Andersson, S., \& Schelander, B. (1975). Lovande tillvaxt hos introduceradegranprovenienser i en kombinerad klonoch froplantsplantage i norra Uppland. Sver. skogsvardsford. tidskr., Bd.73(N3), 277-286.

Giertych, M. (1976). Summary results of the IUFRO 1938 Norway spruce (Piceaabies (L.) Karst) provenance experiment. Height growth. Silvae Genet., Bd. 25(N5-6), 154-164. 
GOST (State Standards)(1983). Environment protection. Soils. Classification of chemicals for pollution control.

Krutzsch, P. (1975). Die Pflanzschulenergebniss eines inventierenden Fichtenherkunftsversuches. (Picea abies Karst. und Picea obovata Ledeb.). Rapp. ochUppsats. Inst. skogsgenet. Skogshosk., N14, 141.

Maronek, D. M., \& Flint, H. L. (1974). Cold hardiness of needles of Pinus strobus L. as afunction of geographic source. Forest Sci., 20(N2), 135-141.

Moscow (1991). Method of metals determination in plants. Fedorovsky All-Union Scientific Research Institute of Mineral Raw Materials. (AIMRM).

Nicholaevsky, V. S. (1979). Biological basis of plants gas resistance. - Novosibirsk: Nauka, 278.

Pollard, D. F. W., \& Londan, K. T. (1974). The role of free growth in the differentiation ofprovenances of black spruce Picea mariana (Mill.). Can J. Forest Res., 4(N3), 308-311.

SanPin (2002). The sanitary-epidemiological rules and regulations Hygienic requirements to the safety and $\mathrm{mcg} / \mathrm{g}$ nutritional value of foods.

Semakin, V. P. (1968). Clonal selection in gardening. - Moscow: Kolos, 136.

Sergeichik, S. A. (1997). Plants and Ecology. - Minsk: Uradzhay, 224.

Shimadzu. (2008). Atomic absorption spectrophotometer A.A.,- 7000, "Shimadzu" corporation, 1-5.

Stastny, T. (1971). Modifikovanie prejavu genetickej podstaty rastu Larix deciduasMill, vplyvom rozdielnych podmienok prostredia. Lesn. Stud., 10, 101.

Szonyi, L., \& Ujvari, F. (1975). First results of the international (IUFRO) Norway spruceprovenance experiment. Erdesz. Kut., Kot. 71(N2), 139-147.

Vazhenin, I. G. (1987).Guidelines for the study of dispersal principles for emissions in the vicinity of industrial enterprises Dokucheva Soil Institute. Moscow, 145.

Vincet, G. (1974). Produkce ekotypu teze dfeviny, jejich pfenos a kfizeni. Lesnictvi, 20(N8), 717-730.

Wilcox, M. D. (1982). Selection of genetically superior Eucalyptus regna's using family tests. N.Z.J. Forest. Sci., $12(3), 480-493$.

\section{Copyrights}

Copyright for this article is retained by the author(s), with first publication rights granted to the journal.

This is an open-access article distributed under the terms and conditions of the Creative Commons Attribution license (http://creativecommons.org/licenses/by/3.0/). 